\title{
Sueños, Bandas y Pistolas: La Interacción entre la Violencia Adolescente y la Inmigración en un Vecindario de la ciudad de Nueva York
}

\author{
Pedro Mateu-Gelabert iD \\ National Development Research Institutes, Inc. New York.
}

\section{RESUMEN}

Prevenir la violencia entre adolescentes es necesario para conseguir la seguridad de colegios, barrios y de los propios adolescentes, pero la prevención efectiva requiere una comprensión de sus causas. Este informe utiliza cinco años de trabajo de campo en una comunidad inmigrante de la ciudad de Nueva York para describir cómo la distancia generacional que separa a los adolescentes inmigrantes de sus padres, es ampliada por el proceso de inmigración. La experiencia migratoria y la separación generacional llevan a los adolescentes que se sienten amenazados a buscar protección en bandas. Mientras que anteriores investigaciones han explicado la violencia adolescente entre inmigrantes como un producto de la alienación cultural, este informe sugiere que gran parte de la violencia entre estos adolescentes es una respuesta pragmática a las condiciones de inseguridad del vecindario, y que las políticas de prevención debe tener por objetivo garantizar la seguridad de los adolescentes.

Crime prevention is an important task to ensure the safety of schools, neighbourhoods and adolescents, but the design of effective interventions requires an adequate understanding of juvenile delinquency and its causes. This reports is based in a five-year ethnographic study of an immigrant community of New York City to describe how the process of immigration widens the generational gap between parents and their sons. The experience of immigration and the generational gap push adolescents to join gangs in their search for protection from local threats. While previous studies have explained adolescent violence among immigrants as a product of cultural alienation, this study suggest that a great deal of adolescent violence is a pragmatic response to the local conditions of insecurity and that crime prevention policies should aim to provide safety to adolescents.

\section{Introducción}

El número de inmigrantes que encuentran un nuevo hogar en EEUU ha estado aumentando de una forma constante desde 1972. Hoy en día, una quinta parte de la población total de EEUU son inmigrantes (27 millones) o hijos de inmigrantes nacidos en EEUU (28 millones). La mayor parte de estos recién llegados se establecen en las áreas metropolitanas de California, Florida, Nueva Jersey, Nueva York y Texas. Por ejemplo, casi un millón de nuevos inmigrantes llegó a Nueva York entre 1980 y 1990. La inmigración en Nueva York ha tenido tal impacto sobre la población de la ciudad que en 1995, la mitad de los habitantes eran inmigrantes nacidos en el extranjero o hijos de inmigrantes. (Departamento de Planificación de la Ciudad de Nueva York, 1996). Muchos de los inmigrantes son niños y adolescentes; casi un tercio de los estudiantes 
de las escuelas públicas de la ciudad de Nueva York son inmigrantes (Rivera-Batiz, 1996).

Este informe se centra en el efecto que la inmigración tiene sobre la relación entre adolescentes y padres inmigrantes, y en la adaptación de los adolescentes al vecindario en el que sus familias se han establecido. Basado en la experiencia de inmigración de un grupo de 25 familias, la mayoría de la República Dominicana, explico cómo, presionados por el desempleo de su país natal, los inmigrantes Dominicanos vienen a EEUU en busca de mejores oportunidades para ellos y para sus hijos, estableciéndose en las áreas interiores de la ciudad (inner city). Tal como ocurrió con previas generaciones, este proceso de inmigración acarrea una desconexión generacional entre padres e hijos inmigrantes. La separación cultural entre padres y adolescentes provoca que los jóvenes recurran a sus compañeros en busca de consejo y como modelos de comportamiento para adaptarse a la realidad, a menudo violenta, con la que se encuentran en su país adoptivo.

Como consecuencia de esta ruptura en el proceso de socialización, y de haberse establecido en un área donde la violencia es frecuente, los adolescentes inmigrantes de primera generación (nacidos en el extranjero) y los de segunda generación (aquellos nacidos en EEUU de padres inmigrantes) adoptan comportamientos violentos para protegerse de las amenazas recibidas por parte de otras personas en su barrio. En otras palabras, los adolescentes inmigrantes adoptan comportamientos violentos y se unen a grupos o bandas violentos como una forma de garantizar su seguridad o como una respuesta directa a amenazas recibidas. Sin embargo, una vez que las circunstancias violentas desaparecen, las relaciones con los grupos violentos también disminuyen o desaparecen.

Otros autores han teorizado que la alienación cultural de la sociedad anfitriona es la razón principal por la que los inmigrantes adolescentes adoptan un comportamiento antisocial y se unen a las bandas. Por mi parte, argumento que la desconexión cultural entre los padres y los hijos sitúa a los adolescentes en una posición vulnerable, creando una oportunidad para que las bandas se presenten como una alternativa más segura y práctica a los valores y comportamientos defendidos por los padres inmigrantes; valores que los jóvenes perciben como obsoletos. Presento la afiliación con grupos violentos de adolescentes no como una cultura de oposición que proviene de la alienación, sino como el vínculo con redes de amistades cuyo objetivo es garantizar la seguridad. La idea de unirse a grupos violentos para obtener seguridad es especialmente atractiva entre aquellos adolescentes cuyos padres son incapaces de ofrecerles consejos sobre la forma en la que deben desenvolverse por el nuevo y a menudo violento entorno.

Me basaré en anteriores investigaciones que sugieren que la emigración, al conllevar una ampliación de la ruptura en el proceso de socialización generacional, contribuye a debilitar la eficacia colectiva del vecindario. Sampson, Raudenbush y Earls (1997) definen la eficacia colectiva como "la cohesión social entre los vecinos junto a su voluntad para intervenir a favor del bien común." La eficacia colectiva explica la delincuencia juvenil como el resultado de la incapacidad colectiva de los adultos para supervisar con eficacia a los grupos jóvenes del barrio. El proceso de emigración debilita la autoridad paterna, limitando la capacidad de los adultos para vigilar a los adolescentes y compartir la supervisión comunitaria del barrio. La falta de una efectiva supervisión por parte de los adultos lleva a los adolescentes inmigrantes a buscar alternativas para garantizar su seguridad, tales como unirse a redes de adolescentes.

Este informe tiene dos objetivos relacionados entre sí: presentar el efecto que la inmigración tiene sobre la cohesión familiar, específicamente sobre la relación entre 
padres e hijos, y presentar cómo la discontinuidad cultural afecta a los procesos de socialización de inmigrantes de primera y segunda generación en el barrio en el que se establecen. Explicaré que la localización física en la que las familias inmigrantes se establecen es de gran importancia para determinar el papel que la desconexión generacional juega entre los adolescentes inmigrantes. Daré un énfasis especial a cómo, dada la ruptura generacional, los adolescentes se adaptan a la violencia que encuentran en los barrios urbanos, adoptando formas de comportamiento aprendidas de sus colegas de vecindario.

La necesidad de adaptarse para hacer frente a la violencia del barrio es un problema que las familias inmigrantes comparten con sus homólogos no inmigrantes. Sin embargo, la inmigración es un factor adicional que aumenta el riesgo de que los jóvenes adopten un comportamiento violento o se unan a las bandas. Esto es debido a que los hijos de los inmigrantes son más dados a confiar exclusivamente en sus colegas para enfrentarse a las tensiones de la violencia y para determinar las mejores tácticas para desenvolverse en las calles de la ciudad. Los padres, al haber crecido en otro país, no pueden recurrir a experiencias pasadas para reconocer indicios de problemas en sus hijos o para entender los problemas que sus hijos estén encontrando. También presento diferencias entre la aculturación de los inmigrantes de primera y segunda generación para mostrar cómo ambos grupos se adaptan a la violencia.

\section{El Estudio}

Los datos presentados en este informe incluyen información recogida como parte de un estudio longitudinal y etnográfico sobre la violencia adolescente patrocinado por el Instituto Vera de Justicia bajo la dirección del Dr. Mercer Sullivan. Trabajé como observador participante en un colegio de un vecindario predominantemente inmigrante de la ciudad de Nueva York. Durante tres años, documenté el desarrollo social de 25 estudiantes, comenzando cuando los estudiantes estaban en séptimo curso y terminando cuando acabaron su primer año de enseñanza secundaria. Además de observar a los adolescente mientras se relacionaban en su escuela y vecindario, entrevisté en profundidad a cada uno de los estudiantes y a sus padres como mínimo una vez al año. Estas entrevistas fueron grabadas y posteriormente transcritas y codificadas con la ayuda de software de análisis cualitativo.

También pasé muchas horas observando las actividades escolares y extraescolares y anoté las situaciones conflictivas y de violencia entre la población estudiantil, en la escuela y el vecindario. La financiación por parte del National Institute of Justice (Fondos de investigación: 199-IJ-CX-0024) hizo posible una cuarta sesión de entrevistas, que se llevaron a cabo con 12 de los 25 miembros iniciales de la muestra (cinco nuevos inmigrantes y siete nacidos en EEUU) para examinar con más detalle la forma en que su historia de inmigración afectaba su desarrollo. Finalmente, pasé diez días en la República Dominicana, donde viajé en la capital y las zonas rurales, visitando familiares de los adolescentes en la muestra y hablando con ellos sobre la experiencia emigratoria de sus familias.

La siguiente tabla explica de forma resumida el número de estudiantes y padres entrevistados durante cada sesión de entrevistas. 
Tabla I: Estudiantes y Padres Entrevistados

\begin{tabular}{|c|c|c|c|c|c|c|c|} 
Sesión 1 & \multicolumn{5}{c|}{ Sesión 2 } & Sesión 4 & \\
\hline Estudiantes & Padres & Estudiantes & Padres & Estudiantes & Padres & Estudiantes & Padres \\
\hline 25 & 25 & 20 & 17 & 19 & 17 & 12 & 0 \\
\hline
\end{tabular}

Una característica interesante de esta comunidad, que ofrece una visión de la relación entre la inmigración y la violencia juvenil, es la coexistencia de primera generación de inmigrantes con diferentes tiempos de residencia en EEUU. Los diferentes niveles de aculturación entre los nuevos inmigrantes y los inmigrantes de la segunda generación provocan diferentes grados de exposición y participación en la violencia y victimización. Por ejemplo, previas investigaciones sugieren que los inmigrantes recientes son menos dados a relacionarse con la delincuencia porque todavía no se han expuesto a los factores de riesgo asociados con las áreas interiores de las ciudades americanas. Algunos ejemplos son evidentes en nuestros datos, junto a ejemplos contrarios de adolescentes inmigrantes recién llegados que adoptan una rápida e intensa trayectoria delincuente ante la brusca confrontación con los violentos desafíos en su nuevo entorno.

\subsection{El Uso de Métodos Cualitativos}

Los métodos cualitativos permiten que tanto el contexto social como la construcción social de significado sean capturados a través del observación y entrevistas en profundidad. El enfoque cualitativo ofrece una puerta a las razones por las que los adolescentes inmigrantes adoptan o no adoptan un comportamiento violento. Esta metodología dio voz a los miembros de la muestra y ofreció una comprensión directa de cómo la inmigración afectó a sus vidas.

Todas las notas de campo y las entrevistas fueron resumidas y codificadas en un programa de ordenador diseñado para analizar datos cualitativos. Para este estudio se utilizaron un total de 2.867 resúmenes de las cuatro sesiones de entrevistas y 593 resúmenes de notas de campo. Todos los datos fueron recogidos durante un período de cinco años, desde 1995 al 2000.

Los resúmenes fueron catalogados con uno o más de los siguientes códigos:

- Banda (Gang): Conflicto causado por bandas de la manzana, las bandas, o incidentes en los que los estudiantes recurren a las bandas como medio de resolver un conflicto.

- Robo: Incidente en el que se quita dinero, ropa u otra propiedad.

- Arma: Incidente en el que se utiliza o se lleva encima un cúter, cuchillo o pistola.

- Asalto: Conflicto en el que un estudiante atacó o amenazó a otro con la ayuda de tres o más amigos.

- Amenaza: Conflicto en el que una persona amenazó a otra con violencia física.

- Sexual: Conflicto relacionado con el sexo.

- Ropa: Conflicto en el que se mofan de la forma en que viste uno.

- Defensa de los amigos: Conflicto en el que una persona es involucrada por defender a amigos o familiares.

- Drogas: Conflicto en el que las drogas están involucradas.

- Vecindario: Descripción o percepción del vecindario.

Revista Española de Investigación Criminólogica 
También se identificó si los datos pertenecían a los padres o los adolescentes y si estos eran inmigrantes de primera o segunda generación. Mientras que el análisis de los datos progresaba, se añadieron los siguientes códigos para capturar algunos de los temas que comenzaban a surgir.

a) Recientes Llegados - Segunda Generación. Este código fue utilizado para codificar diálogos o acontecimientos que se refieren a diferencias percibidas entre los recién llegados y los adolescentes nacidos en EEUU. El siguiente pasaje es un ejemplo extraído de las entrevistas: "Si uno viste al estilo hip-hop a la gente le gusta más. Si viste con colores llamativos le llamarán "Hick" (paleto), que visten como los de la República Dominicana. Si uno sabe cómo vestir no se reirán de él." Otro ejemplo proveniente de una nota de campo: "Orianis ha vuelto al colegio. Fue expulsada durante una semana porque golpeó a un estudiante de otra clase. Orianis está peleándose constantemente. Se altera fácilmente y reacciona golpeando a la persona. Sus compañeros la llaman "campesina" [ha llegado este año a Nueva York].

b) Diferencias de Género. Después de una revisión inicial de los datos, quedó claro que las diferentes expectativas de género eran a menudo una fuente de tensión, especialmente entre padres e hijos. Un ejemplo de un resumen identificado con este código es: "El hombre es expuesto a más cosas en la calle. Lo que uno teme con las mujeres es que un hombre vaya a hacerles daño." Otro ejemplo de las notas de campo: "La directora me dice que a menudo los maestros asumen que "siempre es culpa de los varones". Me explicó que en su experiencia, muchas veces este no es el caso."

c) Diferencias entre los Países. Este código se utiliza en los diálogos donde se hace alusión a las diferencias entre el país natal y el anfitrión. Un ejemplo de las entrevistas es: "Alberto lleva un año en Estados Unidos. Este país le gusta más porque es más bonito. Pero le gusta más la República Dominicana porque es más seguro: "Hay menos atracos y menos asesinatos"' Otro ejemplo, de las notas de campo: "Hoy Aida (profesora del $7^{\circ}$ curso) se reunió con 45 madres y 2 padres. Aida entrego las notas a los padres. Las quejas que Aida tenía sobre los estudiantes eran que no hacía sus deberes y / o que no se comportaban bien en clase, no prestaban atención o hablaban con sus compañeros. Muchos padres acabaron la reunión con la amenaza de "vamos a hablar sobre esto cuando lleguemos a casa". Una madre pegó a su hijo en el hombro con el puño. La madre, como muchos otros hicieron explícita o implícitamente durante la tarde, pidió a la profesora que castigara físicamente a su hijo. Una madre dio permiso para que la maestra pegara a su hijo si se portaba mal, diciendo: "No me gusta la forma 'americana' de hacer las cosas."

d) Diferencias Generacionales. Este codigo se usa en los resúmenes que contienen referencias a diferencias entre padres e hijos. Un ejemplo de un resumen de entrevista: "Francine dice que tiene una doble cara: con su familia "no actúa como una persona madura"; en la calle "actúa como una persona madura." De las notas de campo: "Nydia (una madre que trabaja en la escuela) piensa que ha habido un cambio en el modelo de inmigración dentro de la comunidad. "Antes de los 80 veníamos a trabajar, ahora las drogas y el dinero fácil atrae a los jóvenes."

El analizar los datos de acuerdo con estos temas, controlando por generación e historia de inmigración nos permitió explorar la relación existente entre la inmigración y la violencia. 


\subsection{Selección de la Muestra}

En 1995, seleccioné una muestra de 25 alumnos de séptimo curso que asistían a un instituto júnior de un vecindario inmigrante de la ciudad de Nueva York. Cuando seleccioné la muestra, consideré los siguientes atributos (Tabla II):

- Género: Había 15 muchachos y 10 muchachas de 12 o 13 años de edad, la mayoría provenientes de la República Dominicana. La muestra incluye más varones porque son más dados estar involucrados en delincuencia juvenil.

- Habilidad Académica: Los adolescentes seleccionados presentaban una variabilidad en sus notas académicas. Cinco de ellos eran considerados entre los mejores de la clase, mientras que siete tenían dificultades académicas. El personal de la escuela consideraba los restantes trece alumnos como de habilidad media.

- Lenguaje e inmigración: Doce miembros de la muestra asistían a clases de educación bilingüe. Siete de ellos llevaban en EEUU menos de tres años. Todos los estudiantes eran inmigrantes de primera o de segunda generación. Catorce estudiantes eran de segunda generación, nacidos en EEUU de padres inmigrantes, y 11 nacieron fuera de los Estados Unidos, en la República Dominicana.

- Estudiantes Problemáticos: Para asegurar que la muestra incluía estudiantes que eran considerados "problemáticos", recluté a tres estudiantes asignados a un programa especial para estudiantes con problemas académicos y de comportamiento.

TABLA II: Características de la Muestra

\begin{tabular}{|l|c|}
\hline \multicolumn{1}{|c|}{ Variable } & $\#$ \\
\hline \multicolumn{1}{|c|}{ Género } & \\
Muchachos & 15 \\
Muchachas Etnia & 10 \\
\hline $\begin{array}{l}\text { Dominicanos } \\
\text { Cubanos } \\
\text { Puertorriqueños }\end{array}$ & 21 \\
\hline \multicolumn{1}{|c|}{ Media de hermanos en casa } & 1 \\
\hline \multicolumn{1}{|c|}{ Media de hermanos } & 3 \\
\hline $\begin{array}{l}\text { Media de cambios residenciales durante el } \\
\text { tiempo que duró la investigación }\end{array}$ & 1,5 \\
\hline \multicolumn{1}{|c|}{ Inmigración } & 2,4 \\
Primera generación & 1,1 \\
Segunda generación & \\
\hline $\begin{array}{l}\text { Hogares con al menos un miembro de la } \\
\text { familia con un trabajo regular. }\end{array}$ & 11 \\
Hogares sin miembros con un trabajo regular. & 14 \\
\hline Beneficios & 17 \\
Hogares que reciben beneficios públicos & 8 \\
Hogares que no reciben beneficios públicos & 11 \\
\hline
\end{tabular}




\subsection{El barrio: El Dorado}

El Dorado, pseudónimo del vecindario donde residen los estudiantes, es un barrio inmigrante de la ciudad de Nueva York. Históricamente, este vecindario ha sido la primera parada en EEUU para muchos inmigrantes. El excedente de nuevos inmigrantes, la mayoría de ellos de la República Dominicana, ha transformado la imagen del vecindario: gran número de restaurantes dominicanos; el español se escucha en tiendas y calles; y la música dominicana (Merengue y Bachata) puede oírse en altavoces de tiendas y coches.

Sin embargo, a pesar de la renovada vitalidad económica traída por el influjo de los recién llegados, el área tiene muchos problemas sociales. En 1995 cuando el estudio comenzó, el $25 \%$ de los residentes tenían ingresos por debajo de la línea de pobreza y el índice de desempleo era del $11 \%$. Además, el $11 \%$ de la población recibía ayuda pública y el $24 \%$ recibía Medicaid (seguro de asistencia medica para residentes de bajos ingresos). La proximidad del barrio a las principales rutas de transporte ha facilitado un gran mercado de drogas que suministra cocaína y heroína a vendedores de droga de toda el área metropolitana de Nueva York.

Las drogas han sido y continúan siendo un serio problema del área. Todos los adolescentes en el estudio eran conscientes de que había muchos vendedores de droga en su barrio. Se pueden ver vendedores de droga (a los que se les llama "tigres") en las esquinas de las manzanas del Dorado. Los padres aconsejan a sus hijos que eviten a los tigres y que si se encuentran con alguna disputa callejera, deben tomar irse en dirección opuesta. Sin embargo, otros residentes consideran la droga como algo que sólo afecta a aquellos que están involucrados en el mercado (la gente que compra y vende). Nelson, un viejo residente del barrio, nos dio su opinión sobre el vecindario y los problemas relacionados con las drogas: "No pierden el tiempo robando. Por aquí uno puede llevar una cadena de oro y no se la quitan. Los tigres prestan atención a sus negocios. Su negocio les acarrea mayores beneficios. Los tiroteos y las guerras (de droga) son entre ellos." Irónicamente, la estadística parece confirmar la intuición de Nelson. Mientras que El Dorado tiene uno de los índices de homicidio más elevados de la ciudad de Nueva York, en las otras categorías de crímenes, el barrio está por debajo de la media de toda la ciudad (Garfield y Abramson, 1994). Otra consecuencia del amplio mercado de droga es la división del vecindario en manzanas "de venta". El negocio de la droga genera divisiones entre las manzanas, ya que los vendedores de droga se apropia de manzanas como su "territorio" convirtiéndolos en áreas de venta de uso exclusivo.

Cinco factores hicieron que este barrio fuese elegido para llevar a cabo la investigación propuesta:

a) La República Dominicana ha sido la fuente número uno de inmigrantes en la ciudad de Nueva York desde 1970 hasta hoy. La mayoría de estos recién llegados inmigrantes es muy joven: el 37 por ciento tiene menos de 18 años (Nueva York City, Department of Planning,1996).

b) La localización del barrio junto a las principales rutas de transporte con otros estados y otros barrios de la ciudad de Nueva York ha facilitado un amplio mercado de droga en el área, engendrando violencia en la competición por "lugares de venta" y durante transacciones. Los mercados de droga han sido correlacionados consistentemente con altos grados de violencia.

c) Como se ha dicho anteriormente, el barrio tiene uno de los índices de homicidio más elevados de la ciudad de Nueva York. 
d) El aumento de la participación dominicana en el trafico de droga a todos los niveles provoca el surgimiento de un nuevo grupo a considerar en el narcotráfico (Garrido 1992).

e) El número de dominicanos que se encuentran en las cárceles del estado de Nueva York ha aumentado. Entre 1986 y 1991 "la fuente principal de crecimiento de la población nacida en el extranjero bajo custodia fue el aumento de presos nacidos en la República Dominicana y en Colombia” (Nygard, 1995).

\section{Revisión de la Literatura}

El estudio de la violencia juvenil y cómo se relaciona con el contexto del barrio ha sido un tema de renovado interés en los últimos años (Samson, Morenoff, y Earls, 1999; Fagan y Wilkinson, 1998; Sullivan, 1989). Ha habido una llamada en el campo de la criminología a investigar más a fondo la correlación entre el desarrollo adolescente y la socialización en el uso de la violencia. Unos cuantos estudios han analizado en profundidad el presente contexto social al que los jóvenes se enfrentan en las zonas úrbanas (Sullivan, 1989; Anderson, 1990, 1994, 2000; Canadá, 1995; Wilkinson y Fagan, 1996).

Estos estudios informan sobre los comportamientos que forman parte del código de conducta actual en las zonas urbanas. Anderson (1994) afirma que hay una inclinación hacia la violencia en las zonas de la ciudad más empobrecidas originada por las circunstancias en la que los habitantes viven: "la falta de trabajos que paguen un salario digno, el estigma de la raza, la secuela del uso y tráfico desenfrenado de la droga, y la resultante alineación y pérdida de esperanza en el futuro" (Anderson, 1994, p. 81). Esta situación lleva al desarrollo de un "código de calle", que Anderson define como "una serie de reglas informales que gobiernan el comportamiento interpersonal público, incluyendo el uso de la violencia" (Anderson, p. 82). Sullivan (1986) presenta cómo diferentes características de los barrios influyen en la socialización de los adolescentes hacia diferentes trayectorias delincuentes $\mathrm{y}$, con mayor importancia, cómo las redes sociales del vecindario ofrecen diferentes formas de acceso a los trabajos y al cese del comportamiento delincuente.

El proceso de aculturación y su vinculación al comportamiento violento también ha sido explicado en recientes estudios que examinaban los grupos de inmigrantes (Chin, 1996; Moore, 1991; Padilla, 1992; Vigil, 1983 y 1988). Previos estudios han demostrado de forma consistente que los jóvenes de padres inmigrantes nacidos en EEUU están más involucrados con el crimen que los recién llegados (Tonry, 1997; Hernández, 1999). Algunos autores (Fernández-Kelly y Schauffler, 1994; Portes y Rumbaut, 1996) cuestionan que esta diferencia se mantenga en las olas más recientes de inmigrantes. Exponen que, debido a la falta de trabajos en la industria y al origen étnico no blanco de los nuevos inmigrantes, estos adolescentes se enfrentan a más discriminación que los primeros inmigrantes que llegaron a los Estados Unidos. Esta discriminación y falta de oportunidades provoca una aculturación en la que los inmigrantes rechazan los valores de la sociedad dominante. Para estos autores, las pandillas representan una opción, una alternativa a los trabajos sin posibilidades y al desempleo ofrecido por la sociedad dominante. Diego Vigil explica que el pertenecer a una pandilla ofrece a los inmigrantes de segunda generación una fuente alternativa de desarrollo personal y de identidad. Otros autores (Moore, 1992; Rodríguez, 1993) han estudiado el tema de la violencia y de formación de bandas, pero hay necesidad de explorar con más profundidad el 
proceso de adaptación de los adolescentes inmigrantes que no se unen a las bandas y evitan una trayectoria violenta.

Una serie de estudios clásicos (Thrasher, 1927; Spergel, 1964) y estudios más recientes (Vigil, 1988; Moore, 1991; Padilla, 1992; Chin, 1996) han examinado la estructura y organización de las pandillas juveniles en los barrios inmigrantes. Estos estudios se han concentrado en los adolescentes de más edad, ya involucrados en actividades criminales serias, pero no han trazado ninguna conexión explícita entre la experiencia inmigrante y el inicio de la actividad delincuente en la adolescencia temprana. Las teorías existentes sobre la desorganización social y la oportunidad de las manzanas han planteado a menudo las relaciones entre la delincuencia y la desventaja social, aplicando estas nociones por igual para explicar el comportamiento de jóvenes inmigrantes y no inmigrantes que viven en los vecindarios urbanos pobres, y sin concentrarse específicamente en los factores relacionados con las condiciones de las comunidades inmigrantes. Este informe extiende estos modelos al incluir como la inmigración afecta la familia y organización del vecindario y como esos cambios se reflejan en el desarrollo de los adolescentes, especialmente en relación con su adaptación a la violencia.

Además, expongo que la adopción de un comportamiento violento, para muchos inmigrantes adolescentes, no es una respuesta cultural a la discriminación, sino una solución a la amenaza física sufrida en un contexto en el que "representar" a un grupo de adolescentes es considerado como una forma de garantizar la propia seguridad. El papel que juega la violencia en la formación y comportamiento de las bandas juveniles es un tema estudiado en la literatura reciente (Decker, 1996; Fleisher, 1998; Miller, 1999). Sin embargo, es menos citado el hecho que una vez los adolescentes salen del barrio, y se disipan las amenazas a su seguridad, su participación en los grupos violentos acaba o disminuye drásticamente.

El presente estudio también difiere con anteriores estudios etnográficos al no centrarse exclusivamente en adolescentes nacidos en los Estados Unidos. Enfatizo la socialización de los inmigrantes de primera generación cuya población va creciendo en las areas céntricas de la ciudad (inner city). Otras investigaciones que examinaron a los inmigrantes lo hicieron centrándose en la afiliación a bandas en el periodo de adolescencia avanzada. Voy mas allá de estos estudios al centrarme en la etapa mas temprana de la adolescencia (12-15 años) y al incluir procesos de adaptación menos conflictivos y no solamente procesos de afiliación a bandas. Sin embargo, como otros autores, presento la adaptación de los adolescentes inmigrantes como un proceso en el que los adolescentes descubren rápidamente que deben aprender a tratar con la violencia generada por el "código de la calle".

Para entender la influencia que la inmigración tiene sobre la violencia juvenil, utilizo una teoría de emigración recientemente expuesta por Waters (1999) en Crime and Immigrant Youth. Waters argumenta que la inmigración debería entenderse como un proceso social que involucra a tres generaciones: los padres inmigrantes, que no han sido socializados en los valores del país anfitrión; los niños, segunda generación, nacidos en el país de sus padres pero socializados en el país anfitrión a través de una dependencia inusual en las relaciones de grupo, colegios, y medios de comunicación; y finalmente, la tercera generación de niños, que son socializados por sus familias de una forma más normativa.

Como Waters, defino el proceso emigratorio como un desacuerdo entre las normas y valores de los padres y las de sus hijos, que están creciendo dentro de un grupo de referencia diferente (un grupo diferente de personas que le indica el comportamiento adecuado) y en un entorno distinto. También mostraré cómo estas 
diferencias entre padres e hijos afectan la adaptación de los adolescentes a su nuevo contexto social (un contexto social caracterizado por la existencia de grupos adolescentes que usan la identificación territorial y la violencia como fuente de orgullo e identidad). En la siguiente sección, Sueños, explicaré cómo diferentes grupos de referencia para padres y adolescentes influyen la forma en la que los inmigrantes dominicanos se adaptan a su nuevo entorno.

Esta investigación también se basa en el concepto de eficacia colectiva. Ese concepto explica por qué el debilitamiento de la autoridad paternal afecta a la delincuencia y violencia juvenil, y también ayuda a explicar cómo barrios con una tasa de pobreza similar pueden tener diferentes índices criminales. Sampson y sus colegas demostraron que la inmigración va ligada a un menor grado de eficacia colectiva. Este artículo ampliara estas investigaciones al explorar las razones de esta conexión entre crimen y inmigración. Describiré cómo la distancia generacional, ampliada por las condiciones de inmigración, debilita el apoyo social de los niños y la capacidad de los padres para saber sobre el paradero y las actividades de sus hijos, dificultando el control de los padres sobre sus hijos. Esta investigación, basada en trabajo etnográfico en un barrio inmigrante, describe y analiza los modelos de violencia juvenil y examina cómo estos modelos de violencia están relacionados con la familia y la organización del barrio bajo las condiciones de inmigración.

\section{Sueños}

A menudo la vida antes de la experiencia inmigrante es descrita por los padres dominicanos como socialmente ideal, con unas relaciones familiares positivas, un amplio círculo de amigos, y buenas relaciones con los vecinos. A pesar de la identificación positiva con el grupo de referencia del país natal, una gran falta de oportunidades laborales sitúa a la familia en grandes dificultades económicas. Hernández y Rivera-Batiz (1997) compara el número de dominicanos que llegan a EEUU con el índice de desempleo de la República Dominicana, mostrando que la cúspide en el número de dominicanos que llegan a EEUU coincide con la cúspide en la diferencia entre los índices de desempleo en la República Dominicana y los Estados Unidos:

Durante los últimos quince años, la República Dominicana ha experimentado una profunda depresión económica. Como el nivel de vida se ha deteriorado, un número mayor de dominicanos buscan en la inmigración una forma de salir de la pobreza. Por eso se marchan en grandes cantidades a EEUU y, especialmente, a la ciudad de Nueva York (Hernández y RiveraBatiz, 1997, p. 27).

La inmigración se considera una alternativa viable al callejón económico sin salida. La inmigración representa un camino al empleo y oportunidades educativas para los hijos. Como la madre de Saida dice:

En el país (natal) las personas son muy agradables. Uno comparte con sus propios vecinos, con los amigos. Los problemas se resuelven mejor que aquí (en el país anfitrión). Uno no encuentra tanto mal (refiriéndose a su vecindario en los Estados Unidos). Todo es tranquilo. Todo es mejor que aquí. Lo que sucede es que uno no tiene dinero para vivir allí; no puede seguir viviendo allí. No tengo casa; no tengo un buen trabajo allí. ¿Cómo puedo continuar?, no puedo. Aquí gano mis dólares, me visto, como.

La posibilidad de una mejor educación para sus hijos también es considerada como una razón importante que lleva a la decisión de emigrar. Como la madre de 
Martin expuso: "Mi país es muy bonito, muy tropical pero no hay seguridad para los hijos, para que ellos puedan crear su propio futuro."

Durante los años de trabajo de campo, los participantes usaron diferentes caracterizaciones (por ejemplo, hablaban del dinero que caía de los árboles) para explicar el atractivo que EEUU tiene para muchos residentes de la República Dominicana, especialmente para aquellos que apenas pueden llegar a fin de mes. En el siguiente extracto, una mujer relata la forma en que sus parientes, residentes en EEUU, describían su experiencia: "Vivir aquí [EEUU] es vivir como Dios, como la última coca cola en el desierto. Todo lo que uno ve es gente encantadora con dinero." Durante el trabajo de campo en la República Dominicana, la gente me explicaba cómo se puede identificar si una familia tiene parientes viviendo en los Estados Unidos a través de su residencia. En los barrios mas favorecidos las casas tenían añadida una segunda planta. En las áreas más pobres, las casas estaban construidas con ladrillos y cemento, en contraposición con las de madera y metal.

Una vez en los Estados Unidos, hay oportunidades laborales disponibles para los inmigrantes, pero al fondo de la escalera social y con salarios bajos. Ganar salarios bajos significa que los padres inmigrantes deben trabajar muchas horas y muchos turnos, lo que dificulta una supervisión efectiva de los hijos. Mientras los padres luchan con sus complicadas vidas diarias, comienzan a idealizar la vida de su país natal describiéndola como una atmósfera más segura y estricta en la que criar a sus hijos. Esta idealización del país natal es importante porque durante los tiempos difíciles, cuando los adolescentes se involucran en situaciones de peligro, los padres recurren a menudo con enviar a sus hijos de vuelta al entorno "ideal" del país de origen.

Mientras los padres van envejeciendo y progresivamente sienten más nostalgia por su país natal, los hijos crecen en un mundo muy diferente del que los padres conocían. Las referencias de la segunda generación no son historias del viejo país contadas por sus padres y otros parientes; sino que más bien, proceden de su vida urbana en los Estados Unidos. Estos adolescentes quieren ropa con estilo, quieren escuchar música diferente y hablar inglés, el idioma de su país natal. Incluso con sus mejores intenciones, los padres tienen una capacidad limitada para ayudar a crecer y educar a sus hijos, puesto que los hijos están enfrentándose a elecciones y situaciones que le son extrañas a los padres. Los padres no pueden basarse en experiencias de su propia adolescencia para dar consejo a sus hijos.

Mientras que la mayoría de los inmigrantes permanecen en trabajos de entrada (trabajando como taxistas o cuidadoras de ancianos, por ejemplo), algunos alcanzan el deseado éxito financiero. El padre de David alcanzó una nivel mas acomodado comprando ropa al por mayor y vendiéndola al por menor en su apartamento. Durante muchos años invirtió sus beneficios comprando tierra en su pueblo natal, en la parte norte de la República Dominicana. Ahora en su ciudad natal le llaman Don David. Cuando visité la República Dominicana tuve la oportunidad de visitar a su familia y sus propiedades. Mientras que montaba una mula para llegar a la colina principal de su propiedad. El encargado me explicó que todo lo que veíamos en el horizonte eran tierras propiedad de Don David.

Otros no son tan afortunados y para ellos, la experiencia americana es extremadamente difícil. El siguiente fragmento describe cómo una mujer, Ana, describía su experiencia inmigrante en EEUU mientras estábamos esperando en el Juzgado de Familias a que se llamase el caso de su hijo. César, el hijo de Ana, fue arrestado al robar una tienda de zapatillas de deporte con algunos de sus amigos, una banda llamada "Araña Negra". 
Ana se casó en la República Dominicana. Me contó: . "Estaba gorda, era bonita, bella, con el pelo largo, nada malo dentro." Ana me contó sus sueños sobre el trabajo, la compra de una casa, "como todo inmigrante". Una vez en los Estados Unidos, las cosas se convirtieron en una pesadilla. "Yo lo perdí todo," describía Ana cómo tenía que compartir una habitación con su familia. Después su padre le dijo que ahora, una vez allí [en los Estados Unidos], estaba sola. Perdió peso. Solía trabajar en Long Island y no podía ver ni supervisar a su hijo. César pronto comenzó a quedarse fuera hasta tarde, sin que nadie lo vigilara. Lo envió de vuelta a la República Dominicana durante un período para ver si las cosas mejoraban. Sin embargo, una vez de vuelta César se metió en problemas otra vez. Hoy mientras esperábamos en el juzgado, Ana me contó que han cortado la electricidad en su casa, que han desconectado el teléfono... sin ninguna ayuda de su familia. Se sentía indefensa.

“¡Ay, Dios mío! - no cesaba de repetir -. Si yo lo hubiera sabido...

Es interesante señalar que en ambos casos expuestos aquí, los padres, David y Ana, consideraban la República Dominicana como su hogar, el lugar en el que invertir o volver mientras que sus hijos piensan en EEUU como su país. Es especialmente triste señalar que a pesar de la difícil situación económica de su familia, César agravó la situación al robar las zapatillas de deporte. Esto es una indicación de los dos mundos diferentes en los que César y su madre vivían. Más adelante explicaré con más detalle el importante papel que la ropa y el estilo juegan en las vidas de los jóvenes inmigrantes.

La inmigración provoca una ruptura en la socialización familiar normal. Los hijos de segunda generación se socializan en círculos (en la escuela, en la calle) en los que sus padres no han tenido experiencias previas. Además, los padres y los hijos confían en grupos de referencia diferentes para claves de comportamiento (los grupos de referencia de los padres se encuentran en el país de origen; los grupos de referencia de sus hijos son grupos de amigos en el país anfitrión). El hecho de que los padres y los hijos tengan diferentes grupos de referencia significa que cada generación experimenta el mismo contexto social de forma distinta. Los padres están relativamente contentos con su actual estado socioeconómico en EEUU porque comparan su situación presente con la que dejaron en su país natal, que era peor. Como explicó una madre, María: "En los Estados Unidos, comemos como los ricos de la República Dominicana." Sin embargo, los inmigrantes de segunda generación sienten un alto grado de deprivación relativa porque su grupo de referencia no es la familia ni los amigos del país natal de sus padres, sino los ciudadanos de EEUU muchos con más recursos económicos. Los inmigrantes de segunda generación quieren adquirir los bienes materiales que son los símbolos de estatus social dentro de "su" grupo de referencia a pesar de los limitados recursos económicos de sus familias. El hijo mayor de María fue arrestado por vender marihuana, atraído por la promesa de ganar dinero para comprarse unas zapatillas de deporte. Esta disparidad en la forma en la que los miembros de la misma familia entienden su bienestar relativo ayuda a explicar una más alta de criminalidad en la segunda generación de inmigrantes. Esta tasa es menor en la primera generación. (Tonry, 1997; Hernández, 1999).

\section{Crianza de los hijos}

La eficacia colectiva es un concepto empleado recientemente en la literatura criminológica para explicar las diferencias que existen en la delincuencia de los barrios con características socioeconómicas parecidas. La investigación sugiere que los vecindarios con grupos de adultos capaces de supervisar a grupos de adolescentes son

Revista Española de Investigación Criminólogica 
menos propicios a mostrar índices elevados de actividad criminal. Los padres inmigrantes a menudo hablan de la dificultad en supervisar los adolescentes. La experiencia de la inmigración supone un número adicional de factores estresantes para las familias al disminuir la efectividad maternal/paternal en la supervisión de los hijos adolescentes. La supervisión maternal es debilitada por varios factores inherentes al proceso de inmigración: el trastorno familiar; los diferentes grados de socialización experimentados por los padres y los hijos; la emigración circular (los adolescentes que van y vienen entre EEUU y su país de origen con residencia periódica en ambos países); las diferencias entre los padres inmigrantes y sus hijas adolescentes sobre cuáles son los papeles de género correcto; la incapacidad de los padres para supervisar a sus hijos de la misma forma en la que lo hacían en su país natal; y la percepción de los padres que en EEUU hay restricciones institucionales que limitan su capacidad para disciplinar a sus hijos. Trataré cada uno de estos factores con más profundidad en el siguiente apartado.

Disrupción Familiar. La inmigración provoca la separación de las familias que puede durar años. En el caso de los inmigrantes dominicanos, las madres a menudo dejan a sus hijos con otros miembros de la familia (la mayoría de veces la abuela materna) en el país natal. Una vez que la madre ha podido de establecerse en el nuevo país, pide que sus hijos (a menudo uno a uno durante un período de años) se reúnan con ella. Como resultado, los hijos en su pre- y media adolescencia, después de una larga separación, viven con sus madres por vez primera, durante un significativo período de su desarrollo. La combinación de salir del hogar y país de uno y trasladarse a vivir con alguien que uno considera casi un extraño crea un sentido de alienación que los adolescentes pueden expresar por medio de la desobediencia. Por ejemplo, Héctor creció con su padre y abuela en la República Dominicana hasta que vino a EEUU para vivir con su madre a los 12 años. Desde el día que llegó, su madre sintió que tenía dificultad para controlar a Héctor y éste se fue involucrando progresivamente en un comportamiento violento:

No sé nada sobre lo que Héctor hace. Si está metido en algo malo, o en algo nuevo... pero no quiere ir a la escuela. No quiere escucharme. Le hablo y es como hablar con la pared. Lo que hace es responderme... Voy a enviarle de vuelta. Antes de que comience a vivir en la calle, o caiga en algún vicio o caiga en muchas otras cosas es mejor que lo envíe de vuelta (a la República Dominicana) con su padre que puede controlarlo.

Diferentes Grados y Diferente Rapidez de Socialización. El salto generacional es agravado por la rapidez con la que los adolescentes se socializan en el nuevo país. La tensión normal entre los adolescentes y los padres empeora en las familias inmigrantes debido al hecho de que los padres están menos familiarizados con la cultura del nuevo país y se adaptan a un ritmo más lento que sus hijos. Este salto generacional está más acentuado en los niños de segunda generación, aumentando la distancia y falta entendimiento que existe entre padres (socializados de acuerdo con las normas de su país natal) e hijos (totalmente socializados en el país anfitrión).

Estas diferencias de adaptación se hacen evidentes en dos formas:

a) El desconocimiento paternal sobre los valores y actitudes de la calle. El desconocimiento de los padres sobre la ley de la calle afecta la capacidad de los padres para darse cuenta de indicios que apuntan a que sus hijos estén confrontando dificultades. El siguiente fragmento ilustra lo que sucedió cuando los padres de Saida no percibieron indicios de que su hijo Ángel estaba involucrándose en venta de droga, indicios que para su hija menor eran obvios. Antes del arresto de su hermano, Saida advirtió a su madre que su hermano Ángel "se está moviendo mucho". 
ENTREVISTADOR: Cuénteme algo sobre su hermano (de quince años). ¿Qué sucedió?

SAIDA: ¿Ve la tienda que está cerrada, la que está junto a mi edificio?

ENTREVISTADOR: Sí, la veo.

SAIDA: Estaban vendiendo. Estaban vendiendo marihuana. Y lo metieron en el lío.

ENTREVISTADOR: ¿Estaban vendiendo hierba en el Deli?

SAIDA: Sí, y metieron a mi hermano en ese mundo. Mi hermano eligió hacer eso. Le dijeron que hiciera eso y le convencieron diciéndole que iba a ganar mucho dinero. Uno puede comprarse lo que necesite. Zapatillas de deporte, todas las semanas, cualquier cosa. Así que, se metió dentro por las influencias, ya sabe... Así que en ese edificio, la policía tenía una cámara. Mi hermano, como un tonto pelado, fue arrestado, le pusieron allí, le dieron tres bolsitas, porque era la primera vez que vendía. Le dieron tres bolsitas. Sólo vendió una y se la vendió a un policía. Y lo cogieron por eso. Así que nunca más va a hacerlo otra vez porque esa fue su primera experiencia y mire cómo le ha salido. Imagine.

b) Los padres inmigrantes a menudo necesitan recurrir a sus hijos para tratar con departamentos del gobierno o instituciones cívicas. Este cambio de roles debilita la autoridad de los padres sobre sus hijos. En el caso anterior, Saida tuvo que perder unos días de colegio para acompañar a su madre al juzgado, servirle de traductora con la corte y el abogado, y explicar a su madre todo el proceso que se iba a seguir para llegar a juicio.

La Emigración Circular como una Medida Disciplinaria. Las distintas creencias culturales sostenidas por los adolescentes y los padres pueden también llevar a una medida disciplinaria que parece ser nueva entre los inmigrantes. Muchos padres inmigrantes están convencidos de que la forma de educar a los hijos en su país natal, ahora idealizado en sus mentes, son mejores. Como consecuencia, cuando la seguridad de sus hijos se pone en entredicho o cuando los hijos se involucran en situaciones serias, a menudo los padres deciden enviarlos a la República Dominicana para hacerlos "mas respetuosos y mejor educados." Por ejemplo, la madre de Raúl estaba preocupada porque su hijo estaba "saliendo mucho a la calle." La madre ya había tenido una situación difícil cuando su hijo mayor se afilió con una banda y robó su propia casa. Para evitar resultados parecidos con su hijo mejor, Raúl, decidió enviarlo a la República Dominicana a vivir con su padre hasta que los peores años de la adolescencia pasaran. La madre dijo a Raúl que volviera tan sólo cuando "viniese hecho un hombre." Raúl describe así su experiencia en la República Dominicana:

RAÚL: No me gustaba. Para mí, había estado sin padre durante la mayor parte de mi vida. Mi padre estaba completamente fuera de mi vida desde que tenía ocho años. Era diferente y difícil estar con él. No me gustaba.

ENTREVISTADOR: ¿Ibas a la escuela?

RAÚL: Fui a tres escuelas distintas. Fui expulsado de la primera. No entendía el español y no sabía escribirlo. Sólo fastidiaba y no hacía el trabajo. Dijeron que quemé un papel y arrojé una bomba de odor. No hice nada de eso. Entonces dijeron que ataqué a alguien. Algunos rumoreaban sobre mis amigos y yo... así que fuimos a por ellos y los asustamos. Les dije a la cara que no me gustaba que dijeran mentiras sobre mí. Mis amigos estaban hablando con él. Sólo estaba mirándolo como si quisiera matarle. No golpeamos a nadie.

Aunque los padres creen que enviar a los hijos a su país natal es una medida disciplinaria útil, a menudo el adolescente no se queda en la República Dominicana el tiempo planeado y vuelve a los EE.UU., dejando desatendida la raíz del problema. Para mostrar el alcance de esta práctica, en la muestra de 25 estudiantes, cuatro padres enviaron a sus hijos a la Republica Dominicana a vivir con sus parientes y muchos otros expresaron el deseo de hacerlo. Tantos adolescentes van y vienen entre los EE.UU. y la República Dominicana que en esta última se les conoce como los "Dominican Yo's". 
En el siguiente fragmento, Raúl, justo al volver de la República Dominicana, describe lo que es ser un "dominican Yo", y su experiencia de vivir en ese país después de haber crecido en EE.UU.:

RAÚL: Me consideraban un Yo porque llevaba pantalones anchos. Los policías nos odiaban también.

ENTREVISTADOR: ¿En la República Dominicana? ¿Por qué?

RAÚL: Uno no puede llevar el pelo moderno, llevar pantalones super anchos o llevar pendientes, si no vas a la cárcel. Allí, en la cárcel te pelan te quitan todo.

ENTREVISTADOR: ¿Te llevaron a la cárcel?

RAÚL: Dicen que ese estilo es cosa de matones. Sólo las malas personas visten así. Esto es lo que dicen.

ENTREVISTADOR: ¿Eso es cierto?

RAÚL: No, es una tontería. Solo quieren aferrarse al estereotipo. Se ríen de nosotros.

ENTREVISTADOR: El hecho de que se rian de ustedes, ¿significa que la gente busca pelea con ustedes?

RAÚL: Sí. La gente también es envidiosa porque hablamos ingles y español. Es ignorancia. Sabemos muchas cosas. Piensan que si uno esta en EEUU encuentra dinero en la calle. Y eso no es verdad.

ENTREVISTADOR: Cuénteme mas sobre eso.

RAÚL: Ok. Piensan que Nueva York es una mina de oro, que sólo porque alguien venga de allí es rico. Intentan utilizarnos por nuestro dinero. Quieren salir pero nunca tienen dinero. También hablan de nosotros a nuestras espaldas. Esa es la razón por la que no me gustaba tener amigos dominicanos. La mayoría de mis amigos eran americanos.

ENTREVISTADOR: ¡Estás bromeando ! ¿Cuántos de tus amigos eran americanos?

RAÚL: Formábamos un grupo entero de americanos, porque mi primo los conocía.

ENTREVISTADOR: ¿Teníais algún nombre en especial?

RAÚL: No, sólo nos los pasábamos bien. Éramos diez o doce que merodeabamos la calles. No podíamos estar con otras personas. Algunos de ellos eran buena gente, no hablaban de nosotros a nuestras espaldas.

ENTREVISTADOR: Cuando estaban juntos ¿hablaban inglés?

RAÚL: Claro. No era mas cómodo hablar en inglés. Era demasiado difícil para mí ligar con una chica en español. No sabía tener una buena conversación con ella. No sabía lo que me estaba diciendo la mayor parte del tiempo porque no entendía el español.

Distintas Expectativas sobre roles de Género. Los padres de la muestra permitían que los adolescentes varones permanecieran en la calle sin ninguna supervisión hasta altas horas de la noche. Pero a las hijas, de la misma edad que los varones, no se les permitía estar en la calle sin un adulto o un hermano. A menudo, las chicas se rebelan contra este tratamiento distinto por considerarlo injusto. Este conflicto crea una gran tensión dentro de la familia. Las adolescentes al sentirse injustamente tratadas pierden el respeto por la autoridad de los padres. Esta pérdida de credibilidad, a veces, lleva a una indiferencia por las normas que los padres establecen. Los padres ofrecen varias razones para explicar normas diferentes para hijos e hijas.

\section{(1) Miedo a la violación y sus consecuencias.}

"Pero el problema es que al chico, nosotros como padres les damos como más libertad porque podemos dejar a un chico en cualquier lugar pero no a una chica. Una chica, se supone que uno no debe dejarle que salga a la calle a las nueve o a las diez de la noche. Pero el chico, bien hay corrupción y drogas pero el chico sabe cómo cuidarse mejor que la chica porque pueden violar muy fácilmente a una chica, incluso al salir del edificio y ellas no pueden defenderse." (El padrastro de Hanna).

(2) Miedo a un embarazo no deseado. 
"Uno tiene que tener más cuidado con las chicas. Porque yo no quiero que, después de haberme sacrificado y creído que mi hija va a estudiar y convertirse en alguien en el futuro... y por el estar con un amigo o un novio, se enamore y acabe con una barriga, no, eso no." (La madre de Francine).

(3) La reputación de la hija y de la familia.

La madre de Hilda establece explícitamente esta correlación entre el comportamiento de las hijas adolescentes y su reputación.

"Los chicos pueden salir pero las chicas no. Le digo a mi hija que siga mi ejemplo, ella no me ve en la calle. Si una está en la calle, la gente va a hablar.” (La madre de Hilda).

“No ve que un hombre puede tener cincuenta mil mujeres y nunca pierde?. Ahora si una mujer hace lo mismo, ¿qué se dice? Es una prostituta. Aunque sea ama de casa. (La mamá de Rico).

(4) El género asigna a los adolescentes a distintos espacios sociales.

La madre de Sofía es muy consciente de que está tratando a sus hijos y a su hija de forma diferente. A pesar de las protestas de su hija, cree que está justificado.

"Sofía es dulce y curiosa. Siempre se enfada porque no le permito que haga las cosas que hace William. Ella tiene que estar en casa mas temprano. Los chicos están hechos para la calle. Y las chicas están hechas para la casa."

La mayoría de los padres comparten esta creencia: la madre de Rico lo justifica con connotaciones religiosas.

"Los chicos son diferentes de las chicas. Los chicos pertenecen a la calle. Esto aparece incluso en la Biblia, los hombres son los hombres, los hombres pertenecen a la calle.” (La mamá de Rico).

Diferencias en la Supervisión de los adolescentes. En el país natal, los padres confíaban en la ayuda de amigos y vecinos para vigilar a los hijos. En el nuevo entorno urbano, tales redes sociales no están fácilmente disponibles. De nuevo, los padres hablan de su país natal como un lugar ideal en el que educar a sus hijos, un lugar en el que la supervisión del adolescente incumbe a todos. En contraste con esta visión idealizada de los vecinos, una vez en EEUU, los padres ven a los vecinos como una amenaza para la seguridad de sus hijos; "Aquí uno no sabe quién es quién. No conoce a nadie." La madre de Bienvenido aconsejó a su hijo que evitara a los adolescentes que vivían en su manzana porque eran peligrosos y tenían mala reputación. La mamá de Evelyn prohibió explícitamente a su hija que se relacionara con los vecinos de la manzana porque los consideraba "malas personas."

Percepciones de Restricciones Institucionales. A menudo los padres sienten que su capacidad de disciplinar con éxito a sus hijos es dificultada porque en EEUU cualquier castigo físico puede interpretarse como abuso al menor. La madre de un miembro de la muestra me contó que su hija había denunciado a su marido en la agencia de protección al menor. Ambos padres sintieron que la agencia les trató como criminales. Muchos padres y profesores de origen dominicano repiten lo que se está convirtiendo en una fábula urbana en El Dorado. Un niño amenaza con llamar al servicio de protección del menor cada vez que sus padres intentan disciplinarlo. Los padres, hartos de esta situación, deciden viajar a la República Dominicana con el niño. Tan pronto como el

Revista Española de Investigación Criminólogica 
avión aterriza el padre puede "educar" al niño y enseñarle a respetar a los adultos. La frecuencia con la que se repite esta historia revela que muchos padres creen que sus manos están atadas a la hora de disciplinar a sus hijos en una manera que ellos consideran apropiada y efectiva. En el siguiente fragmento, la mamá de Raúl comparte su versión de la fábula:

El gobierno no permite que los padres disciplinen a sus hijos: uno coge a su hijo y le golpea en el culo y ya te lo quieren quitar por una palmada en el culo. Yo les digo ¿y qué pasa con la palmada que me dio mi hijo? Como le digo yo a él, no voy a hacerle nada aquí, pero cuando llegue a Santo Domingo todo va a resolverse. Voy a hacer como mi amigo hizo con su hijo. Lo cogió y cuando aterrizaron en el aeropuerto le dijo: “Aja, ven aquí. Ahora estamos aquí." Le dio una paliza porque lo había denunciado al servicio de prevención de abuso al menor.

Algunos padres insinúan una correlación directa entre la incapacidad para disciplinar físicamente a los hijos y el comportamiento ilícito de los hijos. Así lo expuso la madre de Luis: "Lo castigo. Nadie puede pararme porque no vivo de la ayuda social. La ciudad no le mantiene. El día que venda drogas es a él, no a la ciudad, a quién van a llevarse."

\section{Bandas y Pistolas}

En la sección anterior hemos explicado cómo la inmigración conduce a una mayor diferencia cultural entre padres e hijos. Esta diferencia crea unas condiciones en las que los adolescentes, al juzgar el consejo de sus padres como inadecuado, desinformado $\mathrm{u}$ obsoleto, recurrirán casi exclusivamente en sus compañeros para aprender las formas mas apropiadas de comportamiento en su nuevo entorno.

El barrio donde los inmigrantes se establecen es particularmente importante. Es en este entorno en el que los recién llegados se socializarán en las costumbres y formas de su nuevo país. Los niños de segunda generación utilizarán el entorno como una fuente fundamental de socialización, y sus habitantes se convertirán en su grupo de referencia. Si el vecindario es violento, los adolescentes pronto tendrán que aprender las normas que organizan la violencia y adoptar aquellos comportamientos que les den mas seguridad.

\subsection{Organización Social del Conflicto Adolescente en el Vecindario}

Nuestro vecindario está muy relacionado con la razón por la que comienzan las peleas. En nuestra comunidad uno tiene que estar alerta de quién está a su alrededor... Uno tiene que pelear para conseguir respeto; la gente te presionará para descubrir si eres un gallina.

Karen, alumna del $8^{\circ}$ curso.

En el barrio, los grupos de jóvenes tienden a concentrarse en áreas que a menudo coinciden con los mercados de droga. Estos grupos de jóvenes pueden considerarse bandas porque son grupos ritualizados, con nombre y a menudo tienen conflictos con bandas de otras manzanas. Estas bandas no son utilizadas directamente por los traficantes de drogas, sino que más bien sirven como una fuente adicional de violencia. Las bandas son un importante riesgo para todos los residentes del área, especialmente los adolescentes.

Las bandas del barrio normalmente se basan en dos o tres manzanas de la calle. Esta división en bandas a menudo obliga a los adolescentes a definir sus lealtades. Muchos estudiantes se identifican como pertenecientes a una manzana. Representan a su manzana, generalmente la manzana donde su casa esta localizada. Francine describió 
"el representar" como una obligación de residencia casi automatica. "Si uno vive en una manzana, tiene que representarla. Tienes que ir a tu manzana y decir que tienes problemas y ellos te ayudarán. Eso quiere decir que le representan." Representar ofrece seguridad; en caso de conflicto (beef), los estudiantes son respaldados (back up) por gente que les cuida las espaldas (watch their back) e intervienen o pelean en su favor en caso de confrontación. Uno se refiere a estas personas como "my peeps".

En el siguiente fragmento, Saida describe una situación de conflicto y realza como cuenta con sus amigos de la manzana para garantizar su seguridad. En este fragmento, la certidumbre de tener apoyo (back up) influye en la manera en que la adolescente soluciona su conflicto.

SAIDA: Conflicto (Beef) es cuando una tiene problemas con otra chica, u otro chico, ¿lo entiendes? Ellos van a por su banda. Van a donde viven y vuelven con su apoyo, con su 'back up". Si una tiene apoyo y deja saber que no lo tiene, le asaltan. Y si uno no tiene apoyo no puede hacer nada al respecto.

ENTREVISTADOR: ¿tu tienes apoyo?

SAIDA: Sí, lo tengo en mi propia manzana... Porque si uno está realmente en la manzana y caes bien a todos, no les gusta que la gente le golpean a uno. Y no soy la clase de chica que busca a su manzana cuando hay problemas, pero si la otra persona lo hace... No voy a dejar que me ataquen así que llamo a mi propia manzana también.

Para Saida y otros miembros de la muestra las personas de su manzana son consideradas una red y recurso de seguridad en caso de conflicto o de situación potencialmente violenta. En la misma entrevista Saida explicó: "Para estar seguro una debe estar con las personas de su manzana. No estar sola en la calle." En el siguiente fragmento, Teresa señaló una implicación de las rígidas fronteras sociales entre manzanas. Las personas de otras manzanas se convierten en una amenaza a la propia seguridad, una fuente potencial de problemas. Durante toda la entrevista Teresa describió a su vecindario como tranquilo y pacífico. Estaba claro que Teresa tan solo se refería a su manzana cuando se refería a su barrio.

\footnotetext{
ENTREVISTADOR: De acuerdo. ¿Cuándo te preocupas por tu seguridad?

TERESA: Cuando estoy fuera de mi manzana.

ENTREVISTADOR: ¿Por qué?

TERESA: Porque hay personas a las que no conozco, y hay personas que conozco que no me gustan. Así que ese es el problema.
}

Estas percepciones del peligro geográficas y sociales tienen unas consecuencias reales para la movilidad de los adolescentes en su entorno inmediato. Teresa refuerza esta idea:

ENTREVISTADOR: ¿Hay lugares a los que vayas aunque sepas que son peligrosos? TERESA: A veces, pero tiene que ser por una buena razón. No salgo de mi manzana.

Desde el punto de vista de los adolescentes, el "representar" (relacionarse con una banda de manzana) produce el beneficio de permitirles pasear por las calles con seguridad porque evita que otros los elijan como víctimas o se metan con ellos. Luís habla convincentemente sobre el aspecto de disuasión de los "peeps" (amigos, conocidos y/o vecinos a los que uno puede recurrir en caso de conflicto): "Saben que no deben molestarme, porque si lo hacen... mis peeps..."

A pesar de que los estudiantes perciben el representar como una fuente de seguridad, la identificación con la manzana sirve a menudo como fuente de conflicto. Cuando dos manzanas "tienen conflicto", los residentes que pertenecen a cada una de las bandas de

Revista Española de Investigación Criminólogica 
las manzanas automáticamente tienen conflicto. A menudo los adolescentes evitan calles con las que su manzana tiene un conflicto. En una ocasión, después de una entrevista, Ali y yo salimos juntos de la escuela. Ali no quería ir por la calle Redwood, una calle cercana a la escuela porque "Redwood tiene problemas con mi manzana". Rico contó un problema parecido y su necesidad de evitar el área de Graytown (vivienda pública) porque había un conflicto entre Graytown y Costa, la manzana de Rico. Después de muchas entrevistas, se hizo evidente que el conocer las trifulcas que existen entre las manzanas es una buena estrategia de seguridad puesto que no saber sobre estos conflictos puede aumentar la posibilidad de convertirse en objetivo para victimización.

Un conflicto entre manzanas puede llegar a la violencia y las personas pueden recurrir a las armas. Durante su primera entrevista, Saida describió el siguiente incidente en el que las personas de su manzana, inclusive su hermano, "cogieron armas":

Un tipo llamado Gerard, empezó a golpear a uno de los nuestros. Empezó a golpearle a él y a su hermano... y los hermanos iban a golpearle a él, pero la otra manzana les sacó una pistola. Así que los dos huyeron corriendo. Pero entonces todos fueron a buscar pistolas. Nuestra manzana y su manzana. Así que todos tenían armas pero no dispararon porque una mujer ya había llamado a los polis y estaban allí.

Los conflictos entre bandas pueden tener una larga historia. A menudo los adolescentes que mejor conocen lo que está sucediendo en la calle pueden contar las historias que condujeron a los conflictos y alianzas actuales. En el siguiente fragmento Sofía describe parte de la historia del conflicto entre Redwood and Cost:

SOFIA: La calle Cost tiene muchos problemas con Redwood porque a Redwood le gusta faltar al respeto. Redwood ataca Cost. Redwood atacó a un tipo de Cost. El tipo se lo dijo a Cost y se molestaron. Ahora Cost dice que son enemigos de Redwood. Creo que Cost y Clermont son amigos ahora. Hicieron las paces.

ENTREVISTADOR: Y ¿quién decide las enemistades? ¿Quién...?

SOFIA: Todo el grupo lo decide.

ENTREVISTADOR: ¿Todo el grupo?

SOFIA: La manzana entera. Si uno va, van todos juntos.

Muchos estudiantes definen a sus amigos y enemigos en función de la manzana a la que pertenecen. Esta fuerte identificación con la manzana conlleva una lealtad extrema. A menudo los adolescentes se refieren a su banda como "familia" porque uno puede acudir a la banda cuando tiene problemas. Los miembros de la manzana son considerados un recurso para ayuda y seguridad. Numerosos casos documentados en las entrevistas y notas de campo indican que cuando en conflictos inicialmente entre dos individuos intervienen bandas se produce un incremento en la severidad de la violencia y en el número de incidentes violentos.

Las bandas de manzana están más a menudo veces en conflicto que sin problemas. A menudo las manzanas establecen alianzas para luchar contra manzanas más poderosas. Los grupos de manzanas luchan en busca de respeto. "Respeto" es el valor por antonomasia en el intercambio entre manzanas. Las amenazas de violencia y el uso de la fuerza física son la moneda con la que se logra respeto. Algunos estudiantes actúan de una forma parecida en sus relaciones personales (luchan para ganar o mantener el respeto).

El conflicto entre las bandas de las manzanas crea la necesidad de apoyo. Si un adolescente tiene problemas con una persona de otra manzana, y tiene un gran grupo de amigos (que pertenecen a su manzana) dispuestos a defenderle, el oponente debe 
también llevar a "su gente" para que la lucha se lleve a cabo con igualdad. Esta necesidad de apoyo se ha convertido en parte de las vida cotidiana de los estudiantes. Cuando Saida estaba en el séptimo curso, siempre quedaba con una amiga después del colegio. Me contó que siempre se iba a casa con alguien. Le pregunté por qué, pensando que su respuesta haría referencia al placer de tener la compañía de su amiga. "Así uno tiene apoyo," me dijo Saida. "Por si acaso alguien te ataca, uno tiene alguien que le apoye."

La continua rivalidad en el vecindario induce a la mayoría de los estudiantes, especialmente a aquellos más involucrados en la "vida de la manzana", a pensar que ningún lugar es seguro. Uno necesita estar constantemente en guardia. Un estudiante comprometido con la banda de su manzana me explicó que pasea con su espalda cerca de la pared así si otra banda quisiera atacarle, "tendría su espalda cubierta". Esta idea de estar en peligro constante es agravada por el "ethos de la calle". El llevar armas constituye un extremo de este ethos. Llevar armas da a los adolescentes seguridad contra la amenaza de otras manzanas; mostrar armas es visto como una forma inmediata de conseguir respeto y, a la vez, probar que uno no tiene miedo de defenderse. A veces cuando el conflicto entre las manzanas se intensifica, es probable que los adolescentes recurran al uso de las armas, como se describe en el siguiente fragmento de notas de campo:

Mientras hablaba con Héctor, me enteré de una pelea que tuvo lugar el viernes en el patio del colegio sobre las cinco de la tarde, durante una actividad extraescolar. Dos chicos de Cost se acercaron a Loco, un chico de Redwood. Uno de los chicos de Cost sacó una pistola e intentó disparar a Loco. El arma se encasquilló y no disparó. Empezaron a pelear a puñetazos. Otros adolescentes de Redwood se metieron en la lucha y le dieron una paliza a uno de los adolescentes de Cost. Héctor no sabía las razones de la pelea. Parecía que Loco había insultado a la prima de uno de los chicos de Cost.

La división del vecindario en bandas de manzana y las normas sociales que operan dentro del vecindario influyen las vidas diarias de todos los adolescentes. Una forma de documentar la existencia de normas no escritas es presentar la consciencia de su trasgresión tal y como hace Ali en este dialogo al referirse a su amistad con Ario.

\section{ALI: Oh, se supone que Ario y yo no podemos ser amigos. \\ ENTREVISTADOR: ¿No? ¿Por qué no? \\ ALI: Porque somos de manzanas diferentes.}

Las armas son parte de la vida diaria del Dorado. La cotidianeidad de las armas de fuego en la vida de los estudiantes se puso de manifiesto durante el primer año de la investigación en el que tanto los padres como los estudiantes describían el oír tiroteos como si fuesen un acontecimiento cotidiano, algo "a lo que uno se acostumbra".

Los adolescentes se acostumbran a la presencia de las armas y a su uso. En el siguiente fragmento, Evelyn describe tres asesinatos que tuvieron lugar en la esquina de su manzana en el periodo de un mes.

EVELYN: La mayoría de esos tipos, ya sabe, los traficantes de droga... Creo que hace un mes, uno fue asesinado. Y pusieron algunas velas por él. Y como, ya sabes, unas dos semanas más tarde otro fue asesinado.

ENTREVISTADOR: ¿Cuándo fue eso?

EVELYN: Creo que fue en abril.

ENTREVISTADOR: ¿Dos fueron asesinados?

EVELYN: Tres. Fueron tres.

ENTREVISTADOR: ¿Mataron a tres en la manzana? ¿Qué edad tenían? 
EVELYN: Creo que tenían menos de 20 o 22 años. No podían tener más de 22 años.

El ser testigos de violencia forma parte de las narrativas en todos los estudiantes de la muestra. Algunos incluso describen la erupción de la violencia como un acontecimiento intrigante, suficientemente interesante como para acercarse y verlo de cerca. Teresa describió así su reacción a un tiroteo desde un coche en el que una niña resultó herida accidentalmente: "Hace una semana vi un tiroteo en el que una chica fue herida. Fue como una película. Fui a verlo."

Otros adolescentes fueron testigos de las consecuencias de la violencia. Por ejemplo, Isis, a las 7:30 de la mañana, de camino a la escuela, vio el cadáver de un hombre asesinado la noche anterior en una disputa de dinero y droga. Todos los miembros de la muestra pueden relatar alguna experiencia relacionada con las armas. Wendy fue testigo de un robo a punta de pistola mientras estaba esperando con su madre en un salón de belleza. Madison describió oír tiros como un suceso de cada noche, añadiendo con cierto sarcasmo "celebran que van a vivir un mes más." A menudo estas experiencias se viven más de cerca y afectan mas directamente. Juan, el hermano de Luis, fue herido de bala en su casa después de una disputa callejera. Cuando visité la casa los agujeros de las balas todavía eran visibles y Juan llevaba la herida vendada. Judith presenció el asesinato de su propia madre a manos de su ex - novio. El hermano de Hilda fue arrestado como sospechoso en un tiroteo en su manzana. Hilda, su madre y Hanna fueron a la comisaría para informarse sobre su arresto.

Las armas están relacionadas con la búsqueda de "respeto", las bandas y ,especialmente, con el mercado de las drogas. Existe la creencia que las armas son una forma rápida de ganar respeto; como dice Ali, "Herbs (personas que no son capaces de defenderse) no llevan armas." Además, muchos consideran llevar armas como un medio de autoprotección. La lógica, según Saida, es simple: "Si unos tienen protección (llevan pistola), los otros también deben tenerla." Sacar una pistola sólo puede hacerse si alguien es amenazado con otra arma o en una pelea desigual. Raúl me explicó lo mal que puede verse recurrir al uso de armas durante una pelea justa (pelea uno a uno): "porque sacar una pistola mientras uno está peleando es como si estuviera diciendo que es un cobarde." La mayoría de los adolescentes de la muestra evitan llevar pistolas.

Cuando las bandas están involucradas en el conflicto, aumenta la probabilidad que los adolescentes recurran al uso de pistolas, como una forma de disuasión, a causa de la creencia que los oponentes también llevarán armas. En la sección anterior, expusé el caso en el que se uso una pistola en el patio durante una disputa entre las bandas de Cost y Redwood. Después del incidente la escuela solicitó un incremento en el número de oficiales de seguridad presentes a la salida de los estudiantes. En los días que siguieron el clima de la escuela era tenso ya que se presentía que algo serio estaba a punto de suceder. Durante uno de esos días, pregunté al teniente a cargo del personal adicional de seguridad las razones de su presencia. El teniente respondió con nerviosismo: "Nadie me ha dicho nada. No llevamos chalecos antibalas." En esta situación un adulto profesional, jefe de los guardias de seguridad, a cargo de la seguridad en la escuela, temía por su seguridad como consecuencia de un conflicto entre bandas. Imaginemos como algunos adolescentes se sentirían.

Además de su uso como una forma de ganarse el respeto y como fuente de protección, las armas son parte intrínseca del negocio de las drogas. Las pistolas se utilizan para proteger los mercados. Ali describió como un amigo se enfrentó a un competidor que vendía en su manzana: "Sacó su pistola y dijo, "mejor que dejes de vender o voy a matarte." El hecho de que las pistolas simbolizan tanto el respeto como la protección, y su uso como una herramienta efectiva para evitar o castigar 
transgresiones, hace de su omnipresencia una triste realidad de los adolescentes en los barrios más empobrecidos de la ciudad. Además de ser conscientes de las bandas y de los cuchillos, a medida de que los niños crecen se dan cuenta de las armas y de su significado. Es especialmente revelador, y preocupante, que durante la segunda ronda de entrevistas, cuando los adolescentes cursaban el octavo curso, casi la mitad de la muestra (10 de los 25 miembros), eran capaces de identificar dónde podían comprar una pistola y el costo aproximado. Algunos incluso conocían información más especifica, por ejemplo, me explicaron que las pistolas "que llevan muerto" (utilizadas en un homicidio) son mucho más baratas.

La presencia y el uso de armas en el vecindario afectan la percepción de seguridad de los adolescentes, aumentando su inseguridad y convenciéndoles de la necesidad de protección -protección que muchos encuentran en bandas y armas-. Luis, a pesar de su aspecto rudo y su imagen pública de no tener nunca miedo, cuando le pregunté si estaba preocupado por su seguridad respondió: "Ve por la noche sobre las diez o más tarde, veo a traficantes de droga y crackeros que empiezan a tirar tiros al aire. Esos son las únicas veces que me preocupo."

Estas condiciones son las que inmigrantes recientes tienen que adaptarse rápidamente. Esta realidad de bandas es su nuevo entorno. A los recién llegados se les llama peyorativamente hicks (paletos). Los hicks son jóvenes que no están muy versados en las formas de la ciudad (por ejemplo, no hablan inglés o "no saben cómo vestir"). A veces esta incapacidad de encajar y de adaptarse a las formas del nuevo país les convierte en objetivos fáciles, fáciles de asustar o robar, un medio de ganarse el respeto. En un principio no son aceptados por las bandas y deben formar sus propios grupos. A veces esto significa encontrar sus propios recursos para protegerse y desarrollar conexiones con aquellos que son etiquetados al igual que ellos. En el siguiente fragmento Sofía describe un hick:

\footnotetext{
Una persona que no se lleva con la peña. Una persona que viste colores brillantes. Una persona que sólo habla español. Una persona que utiliza palabras dominicanas. Son como campesinos que llegan con una yola [balsa], como eso. No aprenden mucho porque están en clases de hicks. En clases con personas de habla española. Y llevan colores fuera de lugar.
}

Teresa explica cómo victimar a los recién llegados es raramente una fuente de estigma: "Algunos tipos, y son realmente populares, quitan el dinero a los hicks." Este conflicto entre miembros de un mismo grupo étnico pasa a menudo desapercibido en la literatura científica al centrarse en el conflicto existente entre diferentes grupos étnicos. En realidad, muchos recién llegados de la muestra se han quejado de ser objeto de humillación. En una ocasión, Bienvenido fue robado por la banda de la manzana donde residía, lo que indica claramente que la residencia no es un requisito suficiente para pertenecer y tener el apoyo de las bandas.

\section{2. ¿Por qué la ciudad de Nueva York es diferente?}

Como se ha dicho antes, los padres consideran que Nueva York es menos seguro que la República Dominicana por varias razones:

a) En Nueva York no se conocen a los vecinos y hay una falta de confianza entre ellos, mientras que en la República Dominicana se conoce personalmente a los vecinos. La gente siente que pueden confiar en sus vecinos y buscar ayuda en ellos.

b) Hay más armas en las calles de Nueva York.

c) Hay bandas en Nueva York.

Revista Española de Investigación Criminólogica 
d) Hay un aumento de violencia debido al narcotráfico en Nueva York.

Como consecuencia de estas percepciones, los padres inmigrantes tienden a pasar la mayor parte del tiempo dentro de casa y les gustaría que sus hijos hicieran lo mismo. Por ejemplo, los padres de Evelyn limitaron su tiempo en la calle y las actividades a las que podía asistir al principio de su adolescencia. En el siguiente fragmento, la madre de Rico describe las razones de sus miedos:

\begin{abstract}
MADRE DE RICO: Hay muchas peleas en esta manzana. Muchas.
ENTREVISTADOR: ¿Por qué hay tantas peleas?

MADRE DE RICO: Porque hay mucha droga. Hay muchos delincuentes. En mitad del verano uno los ve, especialmente en esta calle, la Avenida Cost y Herman. Uno ve que la calle nunca duerme. Muchos jóvenes se quedan en la calle toda la noche. Además, iqué busca un adolescente en la calle a la una o las dos de la mañana? No puede ser nada bueno. ¿Qué puede encontrar uno en la calle? Pues, un tiro o que lo maten, o que lo apuñalen. Si uno está en casa, mire sólo salgo de aquí para ir a mis citas. Quizá en el fin de semana visitaré a mi hermana que vive en la calle Taylor. Voy a visitar a mi padre que vive en la calle Novena. Esas son las visitas que hago, mi terapia, mi cita con el médico a la vuelta de la esquina. Si estoy en la calle quizá tomando el aire y viendo a la gente, y empieza un tiroteo, y me dan. Sólo por estar allí sin nada que ver. Así que por eso le digo a Rico, especialmente a Rico (el hijo más joven), que se quede a mi lado. A mi lado no le pasará nada.
\end{abstract}

Los adolescentes comparten una percepción similar. En la Republica Dominicana hay violencia adolescente; los recién llegados cuentan de las peleas que tuvieron allí. Incluso admiten que hay más peleas en las escuelas de la República Dominicana (a pesar del uso de castigo físico por parte de muchos profesores). Sin embargo, explican, la violencia en la República Dominicana no está organizada por bandas o "gangs". La percepción de peligro y mayor inseguridad en EEUU son debidos a la existencia de bandas (que no existían hasta hace poco en la República Dominicana) y al uso de armas (cuchillos y pistolas.) La organización de la violencia en bandas en EEUU lleva a un aumento progresivo del conflicto, incrementando la probabilidad de que los adolescentes se involucren con grupos violentos y usen armas.

En el siguiente fragmento, Bienvenido, recientemente llegado de la República Dominicana, describe cómo ve Nueva York:

BIENVENIDO: Aquí (en Nueva York) se está mejor porque allí (en la República Dominicana) no nos dan almuerzos. No nos dan comida y uno tiene que comprarla y llevarla al colegio.

ENTREVISTADOR: Y cuando hay peleas, ¿se pelea más allí que aquí?

BIENVENIDO: Allí pelean mucho pero no como aquí con navajas y todo eso.

ENTREVISTADOR: ¿Usan navajas aquí?

BIENVENIDO: Eso es lo que he oído. Y forman bandas.

ENTREVISTADOR: ¿Bandas?

BIENVENIDO: Gangs.

\title{
7. Adaptación de los Jóvenes Inmigrantes
}

En las dos secciones anteriores establecimos la vulnerabilidad de los adolescentes inmigrantes debido a su creciente necesidad de confiar en sus colegas como modelos de comportamiento a seguir, bajo cuyo consejo y ejemplo se adaptan al país anfitrión. Esta situación es especialmente difícil cuando el barrio en el que se establecen es violento. En esta sección, explico cómo el proceso de inmigración ha afectado a los doce miembros de la muestra entrevistados el último año del estudio y cómo se han adaptado. Cinco de los adolescentes (Héctor, Isis, Martin, Antonio y 
David) son nuevos inmigrantes y siete (Rául, Evelyn, Francine, Hanna, Wendy, Ali y Elsa) son de segunda generación, nacidos en los EE.UU.

Algunos de los adolescentes optaron por acceder a los bienes materiales a través de los medios inmediatamente disponibles para ellos en el vecindario (el negocio de la droga), otros se hicieron miembros de las bandas del vecindario. Todos los adolescentes tuvieron que tratar con la violencia y amenazas a su seguridad física. La mayoría optó por un uso pragmático de las bandas: ser parte de bandas cuando era necesario y alejarse progresivamente cuando no ofrecen seguridad o cuando los adolescentes ya no perciben amenazas a su seguridad.

\subsection{Nuevos Inmigrantes}

Los cinco estudiantes tienen en sus historias familiares claros ejemplos de la separación provocada por la inmigración. Todos pasaron gran parte de su infancia en la República Dominicana bajo la supervisión de sus abuelas, excepto Héctor, que creció con su padre pero también en la República Dominicana. Todos los padres habían decidido inmigrar a EEUU en busca de una vida mejor y fueron obligados a dejar sus hijos. Su suerte varió. El padre de David pasó de ser uno de los vecinos de un área rural empobrecida de la República Dominicana a un hombre de negocios admirado en su ciudad natal. El padre de Antonio se hizó taxista, frustrándose progresivamente debido a su limitada ganancia y al hecho de que no podía utilizar sus habilidades profesionales como contable. La madre de Isis cayó enferma y ahora recibe SSI (Paga de la Seguridad Social), viviendo con su hijo en una habitación de un apartamento compartido con otras familias. La madre de Martin trabajó en una fábrica, perdió el empleo y comenzó a trabajar en una lavandería por cinco dólares la hora. La madre de Héctor trabaja como asistenta de hogar.

De los cinco adolescentes, Isis y Héctor han experimentado el proceso de socialización más violento. A menudo tenían problemas en el colegio. Ambos eran amonestados por pelearse y "agredir" a otros. Una vez en el instituto, robaron a jóvenes en el metro. Isis ya había robado a otro estudiante en la escuela y lo amenazó una vez que la víctima informó del incidente al director. Tanto la madre de Héctor como la de Isis se sentían frustradas por su incapacidad de controlar el comportamiento de sus hijos. En el octavo curso, se les propuso que recibieran Educación Especial. Ambos abandonaron el instituto durante su primer año. La madre de Héctor lo envió a la República Dominicana durante unos meses bajo la supervisión de su padre. Héctor e Isis asistían a programas extra-escolares antes del instituto de forma esporádica y pasaban la mayor parte del tiempo después de clase paseando con los amigos. Héctor e Isis se unieron cada vez más a las bandas de sus respectivas manzanas. Ahora, con diecisiete años, ambos han sido arrestados y venden droga en su manzana. El vendedor de droga de su manzana reclutó a Héctor. Héctor combina el trabajo temporal en construcción con la venta de droga cuando el primero no está disponible. Héctor prefiere la construcción (ofrece mejores horas, una paga similar, y menos riesgos). Su deseo de comprar ropa de marca, fumar marihuana, comprar zapatillas para su novia, y tener dinero en el bolsillo requiere una fuente constante de ingreso: legal cuando es posible, ilegal cuando no. Su madre no puede darle este dinero porque, además de los gastos que tiene en EEUU como cabeza de familia (también tiene una hija de cinco años), está enviando dinero muy necesitado a su familia en la República Dominicana. Como ella dijo, "mi familia es pobre. Aunque sólo sea mensualmente uno tiene que enviar su granito de arena." 
Martin, Antonio y David tuvieron una socialización más positiva. Los tres aprendieron poco después de su llegada sobre la organización de las bandas y cómo evitarlas. A David le robaron en el séptimo curso. Antonio fue amenazado a punta de pistola. Ambos fueron testigos de numerosos asaltos. Antonio vive en un edificio que durante el período de estudio se utilizaba como punto de venta de droga. Aprendió a ser amable con los "tigres" a la vez que mantenía una distancia de seguridad. Martin, Antonio y David asistieron a programas extraescolares antes de atender el instituto. Mientras asistían a la escuela, localizada cerca de sus casas, sus padres se aseguraban que después de las actividades escolares jugaban en casa o estaban con vecinos en los que podían confiar. Ninguno de ellos se afilió con bandas del vecindario.

Una vez que llegaron al instituto, Antonio y David, a pesar de saber poco inglés inicialmente, sobresalieron académicamente. A Martin los estudios le fueron mas difíciles. Ahora se ha matriculado en una academia para prepararse para incorporarse a las fuerzas armadas. Antonio y David trabajan después de clase. David trabaja en el almacén de su padre y Antonio trabaja para una cadena de comida rápida. Después de dos años allí, Antonio es ya encargado. Estos ejemplos muestran que la habilidad de los padres para supervisar con efectividad a sus hijos, y la habilidad de los niños para adaptarse rápidamente a las instituciones anfitrionas, especialmente a la escuela, llevan a una socialización positiva.

A pesar de una socialización positiva inicial, una vez en el instituto, Martin y David establecieron amistad con bandas después de recibir amenazas de otros estudiantes. Las bandas sirvieron como protección y las amenazas no se vieron materializadas. En ambos casos esta protección de bandas es especialmente significativa porque se dio al principio de su educación secundaria, en un instituto diferente, en un vecindario lejos de casa. Esta amistad inicial llevó a David y a Martin a pasar tiempo con las bandas después de clase. Este contacto con la banda indica que a pesar de su convicción inicial de que "las bandas son algo malo", su percepción cambió cuando esas bandas se convirtieron en la primera y más efectiva forma de defensa contra las amenazas de violencia en su instituto.

\subsection{Nacidos en América}

Todos los adolescentes nacidos en EEUU (Raúl, Evelyn, Francine, Hanna, Wendy, Ali y Elsa) crecieron en El Dorado. Sus padres tenían diferentes profesiones, todas con un salario bajo. Raúl vive con su madre que trabaja de recepcionista. Su padre vive en la República Dominicana. La madre de Evelyn también trabaja de recepcionista y su padre trabaja de empleado en una farmacia. Francine y Elsa viven con sus madres, ambas reciben ayuda social. La madre de Hanna trabaja de ayudante de profesora y su padrastro trabajaba en una fábrica hasta que sufrió un accidente de trabajo. La madre de Wendy es trabajadora social; la madre de Ali trabaja limpiando oficinas.

Todos estos adolescentes conocen a los miembros de la banda de su manzana y tienen amigos o parientes que se han sido miembros de bandas. Al principio de su adolescencia, todos ellos excepto Evelyn se identificaban con la banda de sus respectivas calles. Cuatro de ellos (Hanna, Wendy, Ali y Elsa) se involucraron en comportamientos violentos como luchas, asaltos, amenazas a otros con esos grupos de adolescentes y, a veces, llevaban "cuters" para protegerse. Más adelante, una vez que asistieron al instituto fuera del vecindario, todo cambió. Sólo Elsa, que dejó el instituto y pasa la mayor parte del tiempo en El Dorado, todavía se identifica con una banda. Los otros han rechazado su identidad como miembros de la banda. Elsa está en libertad 
condicional por una pelea en la que arrancó de un mordisco parte de la oreja de su oponente.

Raúl, al principio de su adolescencia, estaba más preocupado por el break-dance que por las bandas. Pasaba la mayor parte del tiempo en cursos extraescolares o con un buen amigo bailando. Rechazaba las bandas como una forma de cobardía por parte de personas incapaces de "cuidarse de sus propios asuntos". Sin embargo, más tarde, durante su segundo año en el instituto, comenzó a relacionarse con amigos que pertenecía la banda conocida como Latin Kings. Ahora se considera uno de ellos. Su madre, en un intento de romper esta relación, envió a Raúl a la República Dominicana. Como se ha dicho anteriormente, la estrategia fracasó. Raúl fue expulsado de tres escuelas, seguía metiéndose en problemas, y finalmente tuvo que volver. Raúl, recién llegado de la República Dominicana, está buscando un trabajo y continúa siendo un miembro de los Latin Kings.

Evelyn y su hermana Anna definen su adolescencia durante sus primeros años de instituto como crecer "entre cuatro paredes". Sus padres estaban tan preocupados por su seguridad y por la posible mala influencia de su vecindario que durante su adolescencia el tiempo de ambas hijas era controlado muy de cerca. Sólo se les permitía asistir a clase. Después de clase se les obligaba a estar en casa o tan solo se les permitía salir acompañadas por un adulto. Aunque Evelyn y Anne conocen a todos los adolescentes que pertenecen a la banda de su manzana, no se les permitió estar en la calle sin supervisión adulta. Evelyn and Anne están asistiendo ahora a un instituto alternativo y están muy involucradas en su trabajo académico y en otras actividades escolares. Ahora, son mas críticas de la banda de su calle, después que sus miembros agredieran al novio de Evelyn. "Piensan que la manzana es suya," explicó Evelyn críticamente.

Hanna y Francine son madres adolescentes. Su pronta identificación con la banda de su calle creó tensión entre ellas y sus padres. La tensión se hizo extrema cuando sus madres descubrieron que tenían novios que pertenecían a bandas. Ambas fueron amenazadas con ser enviadas a la República Dominicana si no dejaban esas relaciones. Francine viajo a la República Dominicana por unos meses sin conseguir el resultado esperado. Poco después de su vuelta a EEUU se quedó embarazada. "Ahora puedo hacer lo que quiero en mi casa," dice. Con la maternidad llegó un punto de vista más crítico con respecto a las bandas. Francine ahora rechaza el comportamiento de la calle viéndolo como algo infantil y es especialmente crítica con las adolescentes de su edad que se pasan el día con los miembros de la banda "porque follan con todos."

Tanto Wendy como Ali trabajan mientras atienden el instituto. Ali comenzó a trabajar para una empresa de limpieza, y Wendy trabaja en un almacén de ropa a la vez que asiste a un pequeño instituto alternativo. Hoy día, hablan de sus viejas peleas y de su afiliación a bandas como propias de un comportamiento infantil, algo que han dejado atrás al crecer.

\section{Sumario y Conclusiones}

He explicado el riesgo que la migración supone para los adolescentes, centrándome especialmente en la discontinuidad cultural que ocurre dentro de las familias inmigrantes. Los padres socializados en su país natal intenta educar y disciplinar a sus hijos de unas formas que los adolescentes consideran anticuadas e inaceptadas en el nuevo país. Al mismo tiempo, los adolescentes tienen que socializarse, o aprender cómo comportarse, en esferas (en la escuela y en la calle) en las que sus padres no han tenido ninguna experiencia previa sobre la que basarse para guiar a sus hijos. Esto crea una situación en la que los adolescentes piensan que deben buscar a sus 
colegas para consejo y como modelos de cómo adaptarse a su nueva realidad. El proceso de adaptación y socialización en el nuevo país también está influenciado por las características del vecindario y por la organización social de la violencia que impregna el área. Los jóvenes inmigrantes deben aprender a moverse en un territorio violento y aprender de aquellos de su misma edad para ser aceptados y estar seguros.

Las características del barrio son de gran importancia para comprender el proceso de inmigración y cómo se relaciona con la violencia. Los adolescentes recién llegados deben adaptarse rápidamente para evitar ser víctimas, y a menudo adoptan comportamientos violentos como una forma de adaptarse al nuevo entorno. Los adolescentes de segunda generación crecen en este entorno, en el que se utiliza la violencia como medio de conseguir y mantener el respeto de la manzana. Representar a la manzana de uno es parte de la formación de la identidad de los adolescentes. La manzana ofrece seguridad, define las relaciones sociales apropiadas e identifica quienes son los enemigos.

Para la mayoría de los adolescentes de la muestra, la afiliación con bandas era resultado de un comportamiento aprendido en el vecindario. Una de las razones más convincentes ofrecidas para explicar su deseo de afiliarse con las bandas es que son una fuente de seguridad. Para muchos adolescentes, esta afiliación es claramente contextual puesto que cuando van creciendo y asisten al instituto fuera del entorno violento de su vecindario, su relación con los grupos violentos disminuye. Muchos incluso cambian su visión, considerando este tipo de violencia como circunscrita al barrio de residencia e infantil. Otra prueba de esta tesis que sostiene que la identificación con grupos violentos es resultado de una necesidad contextual son las experiencias de los nuevos inmigrantes. Mientras asistían a la escuela primaria, no se relacionaban con bandas, pero lo hicieron en el instituto. Después de recibir amenazas entablaron amistan con miembros una banda y se unieron a ella, como fuente de protección.

Para prevenir que los adolescentes inmigrantes se unan a grupos violentos necesitamos ofrecerles entornos seguros en los que puedan adaptarse a las nuevas costumbres de EEUU sin tener que recurrir a estos grupos en busca de seguridad. La escuela, las clases, los pasillos y las cafeterías deberían ser seguros. Después de clase, se necesitan lugares que ofrezcan actividades extraescolares supervisadas para ofrecer a los adolescentes una alternativa a la calle.

Tanto los inmigrantes recién llegados como los adolescentes de segunda generación hablan de la necesidad de tener su propia fuente de ingresos, debido a los limitados recursos de sus familias y a la fuerte presión por vestir con estilo y tener ciertos bienes materiales. Además, algunos adolescentes inmigrantes se han convertido en padres muy jóvenes. La mayoría de los miembros de la muestra han tenido empleo y ayudan económicamente a sus familias. Algunos trabajan legalmente (Antonio es el encargado de un almacén de comida rápida; David trabaja en la zapatería de su padre; Wendy trabaja en una tienda de ropa), algunos ilegalmente (Isis vende marihuana), y otros combinan ambas alternativas (Héctor trabaja en la construcción y vende drogas.) Suministrar oportunidades de trabajo, especialmente durante el verano, ayudaría a satisfacer esta necesidad de dinero, permitiendo que los adolescentes ayudasen económicamente a sus familias, y reduciría su necesidad de correr riesgos al buscar fuentes ilegales de dinero. Cuando tuvo oportunidad de elegir, Héctor optó por un trabajo legal.

Como hemos visto, el proceso de inmigración crea un amplio salto generacional. Es importante que las instituciones anfitrionas, como los colegios, las agencias de protección a menores, y las agencias de justicia juvenil, tomen un papel activo en el proceso de informar a los padres inmigrantes sobre los riesgos de seguridad a los que 
sus hijos se enfrenten en sus barrios. Además, hay una necesidad de clarificar a los padres inmigrantes que constituye abuso físico al menor. Las instituciones que sirven a las familias inmigrantes necesitan llegar a los padres y hacerles saber que no constituyen una amenaza para las familias inmigrantes.

La situación de los adolescentes inmigrantes de segunda generación también es difícil. Puesto que nacieron en los Estados Unidos, no se identifican con los recién llegados de la República Dominicana, a los que consideran que están culturalmente menos "en onda" y no bien adaptados. Esta situación es particularmente evidente cuando los niños de segunda generación son enviados a la República Dominicana y se sienten como extraños en lo que sus padres todavía consideran su país. Para los adolescentes inmigrantes de primera generación, la dificultad radica en adaptarse rápidamente al nuevo entorno en el que la violencia y la lealtad a un grupo son lecciones importantes. El ser definido como un hick (paleto) supone una amenaza a la seguridad y al estatus entre adolescentes. Hay una gran presión para socializarse rápidamente en las nuevas costumbres de los Estados Unidos. Irónicamente, hay un paralelismo entre ser un 'hick' en EEUU y un 'Dominican Yo' en la República Dominicana. Esto es un recordatorio del difícil proceso de adaptación que atraviesan los adolescentes inmigrantes, a menudo atrapados entre dos mundos sin pertenecer completamente a ninguno de ellos. 


\section{BIBLIOGRAFIA}

Anderson, Elijah. Code of the Street. New York/London: W.W. Norton \& Company, 1999.

Anderson, Elijah. StreetWise: Race, Class, and Change in an Urban Community. Chicago: The University of Chicago Press, 1990.

Anderson, Elijah. "The Code of the Streets." The Atlantic Monthly (May 1994).

Blumstein, Alfred. "Youth Violence, Guns, and the Illicit-Drug Industry." The Journal of Criminal Law and Criminology 86, no. 1 (1995): 10-36. Press, 1995.

Bourgois, Philippe. In Search of Respect. Cambridge: Cambridge University

Bourgois, Philippe. "Crack in Spanish Harlem. Culture and Economy in the Inner City." Anthropology Today 5, no. 4 (August 1989).

Canada, Geoffrey. FistStickKnifeGun. Boston: Beacon Press, 1995.

Chin, K.-L. Chinatown Gangs: Extortion, Enterprise, and Ethnicity. New York: Oxford University Press, 1996.

Decker, Scott H. "Collective and Normative Features of Gang Violence." Justice Quarterly 11 (1996): 243-264.

Elliott, Delbert S. "Serious Violent Offenders: Onset, Developmental Course, and Termination-The American Society of Criminology 1993 presidential address," Criminology 32 (1994): 1-21.

Fagan, Jeffrey and Deanna L. Wilkinson. "Guns, Youth Violence and Social Identity in Inner Cities." Youth Violence, Crime and Justice. A Review of Research. Vol. 24 (1998).

Fernandez-Kelly, M. P. and R. Schauffler. "Divided Fates: Immigrant Children in a Restructured U.S. Economy." International Migration Review 28 (Winter 1994): 662-689.

Fleisher, Mark. Dead End Kids: Gang Girls and the Boys They Know. Madison, Wisconsin: University of Wisconsin Press, 1998.

Garfield, Richard and David Abramson. "El Dorado: The Health of a Community." New York: Columbia University Press Health of the Public Program, 1994.

Garrido, F. Dominican Narco-Traffickers. New York Police Department Drug Enforcement Task Force, 1992.

Hernandez, Donald. Children of Immigrants. Health, Adjustment, and Public Assistance. Washington, D.C.: National Academy Press, 1999.

Merton, R.K. Social Theory and Social Structure. Glencoe, IL: The Free Press, 1957.

Miller, Jody. One of the Guys: Girls, Gangs, and Gender. New York: Oxford University Press, 1999.

Moore, Joan W. Going Down to the Barrio. Homeboys and Homegirls in Change. Philadelphia: Temple University Press, 1991.

New York City Department of City Planning. The NEWEST New Yorkers 19901994 (December 1996).

Nygard, C.H. Five Years of Changes in the Hispanic Undercustody Population. New York State Department of Correctional Services, 1995.

Padilla, Felix M. The Gang as an American Enterprise. New Brunswick, N.J. : Rutgers University Press, 1992.

Portes, A. and R. Rumbaut. Immigrant America. Berkeley: University of California Press, 1996.

Revista Española de Investigación Criminólogica

REIC AC-02-04

http://www.criminologia.net

ISSN 1696-9219 
Rivera-Batiz, F. The Education of Immigrant Children: The Case of New York City. Working paper, International Center for Migration, Ethnicity and Citizenship, The New School for Social Research, New York, 1996.

Rodriguez, Luis J. Always Running. La Vida Loca: Gang Days in L.A. Willimantic, CT: Curbstone Press, 1993.

Sampson, R. "Linking Time and Place: Dynamic Contextualism and the Future of Criminological Inquiry." Journal of Research in Crime and Delinquency 30, no. 4 (1993).

Sampson, R., S.W. Raudenbush, and E. Felton. "Neighborhood and Violent Crime: A Multilevel Study of Collective Efficacy.” Science 277 (1997).

Sampson, R., J.D. Morenoff, and E. Felton "Beyond Social Capital: Spatial Dynamics of Collective Efficacy for Children." American Sociological Review 64 (1999).

Shaw, C.R., and H.D. McKay. Social Factors in Juvenile Delinquency: A Study of the Community, the Family, and the Gang in Relation to Delinquent Behavior. Vol. 2 of Report on the Causes of Crime. Washington, D.C.: National Commission on Law Observance and Enforcement, 1931.

Sullivan, Mercer. Getting Paid. Ithaca: Cornell University Press, 1989.

Snyder, Howard N. and Melissa Sickmund. Juvenile Offenders and Victims. A National Report. National Center for Juvenile Justice, 1995.

Spergel, Irving A. Racketville, Slumtown, Haulburg. Chicago: Chicago University Press, 1964.

Thrasher, Frederic. The Gang: A Study of 1,313 Gangs in Chicago. Chicago: Chicago University Press, 1927.

Tonry, Michael, Ed. Ethnicity, Crime, and Immigration. Chicago: The University of Chicago Press, 1997.

Vigil, James Diego. Barrio Gangs: Street Life and Identity in Southern California. Austin: University of Texas Press, 1988.

Vigil, James D. "Chicano Gangs: One Response to Mexican Urban Adaptation in the Los Angeles Area." Urban Anthropology 12 (1983): 45-75.

Waters, Tony. Crime and Immigrant Youth. Thousand Oaks, CA: Sage Publications, 1999.

Wilkinson, Deanna L., and Jeffrey Fagan. "The Role of Firearms in Violence 'Scripts': The Dynamics of Gun Events among Adolescent Males." Law and Contemporary Problems 59 (Winter 1996).

Pedro Mateu Gelabert (Ph.D. New York University, 1998) es sociólogo especializado en etnografía urbana con extensa experiencia en investigación cualitativa en Nueva York. Dr. Mateu Gelabert trabajo en Vera Institute of Justice desde 1995 donde realizó investigaciones sobre violencia y victimización entre adolescentes, violencia e inmigración, uso de drogas y policía. En 2000, fue nombrado Investigador Principal Asociado del National Development Research Institute (NDRI, Inc.) para dirigir la rama etnográfica de dos proyectos: Redes, Normas y Riesgo de VIH entre Jóvenes (NNAHRAY) y Contexto Local y Riesgo de VIH (LOCO). Su trabajo de investigación ha sido publicado y presentado en Europa, Latinoamérica y EEUU.

iD https://orcid.org/0000-0003-4003-3782

Revista Española de Investigación Criminólogica

REIC AC-02-04 http://www.criminologia.net

ISSN 1696-9219

https://doi.org/10.46381/reic.v2i0.13 